OPEN ACCESS

Edited by:

Juarez Antonio Simões Quaresma, Instituto Evandro Chagas, Brazil

Reviewed by:

Renaud Mahieux,

École Normale Supérieure de Lyon,

France

Anne-Mieke Vandamme, KU Leuven, Belgium

Maria Grazia Romanelli,

University of Verona, Italy

*Correspondence: Antonio C. R. Vallinoto

vallinoto@ufpa.br

Specialty section: This article was submitted to Microbial Immunology, a section of the journal

Frontiers in Microbiology

Received: 17 November 2017

Accepted: 26 December 2017

Published: 15 January 2018

Citation:

Vallinoto $A C R$, Santana $B B$, Queiroz MAF, da Silva ANMR, Cayres-Vallinoto IMV, da Costa CA, de Sousa MS and Ishak R (2018)

Family Aggregation of HTLV-1

Infection Associated with

FAS -670A/G Polymorphism:

A Case Report.

Front. Microbiol. 8:2685.

doi: 10.3389/fmicb.2017.02685

\section{Family Aggregation of HTLV-1 Infection Associated with FAS -670A/G Polymorphism: A Case Report}

\author{
Antonio C. R. Vallinoto ${ }^{*}$, Bárbara B. Santana ${ }^{1}$, Maria A. F. Queiroz', \\ Andrea N. M. R. da Silva', Izaura M. V. Cayres-Vallinoto', Carlos A. da Costa'2, \\ Maisa S. de Sousa ${ }^{2}$ and Ricardo Ishak ${ }^{1}$ \\ ${ }^{1}$ Laboratório de Virologia, Instituto de Ciências Biológicas, Universidade Federal do Pará, Belém, Brazil, ${ }^{2}$ Núcleo de \\ Medicina Tropical, Universidade Federal do Pará, Belém, Brazil
}

Human T-lymphotropic virus 1 (HTLV-1) infection has been associated with ATL and inflammatory diseases but remains a neglected health problem. HTLV-1 associated diseases were originally described as sporadic entities, but family aggregations have been reported. Viral, genetic, immunological and behavioral factors were used to explain family clusters, but until now a clear explanation remains uncertain. In the present study we report, for the first time, a family cluster of diseased persons presenting the infection across three generations associated with FAS -670A/G polymorphism.

Keywords: human T-lymphotropic virus 1, family cluster, FAS gene, MBL gene, genetic polymorphism

\section{INTRODUCTION}

HumanT-lymphotropic virus 1 (HTLV-1) is a human retrovirus that causes lifelong infection (Poiesz et al., 1981; Bangham and Matsuoka, 2017). Recent estimate suggests that there are 5-10 million infected persons worldwide but its geographical distribution is heterogeneous, with the infection occurring in Japan, Australo-Melanesia, Caribbean, North and South America, Europe, Central, South and West Africa (Gessain and Cassar, 2012).

Although the infection has been associated with inflammatory and lymphoproliferative diseases (Bangham and Matsuoka, 2017) it remains a neglected health problem and many questions remain unsolved. It is not known why most HTLV-1-infected persons remain asymptomatic and $10 \%$ of them develop clinical symptoms (Kaplan et al., 1990). The presence of the virus is not the only variable associated with disease development once most of people infected with HTLV-1 remain asymptomatic.

Human T-lymphotropic virus 1 (HTLV-1) associated diseases were originally described as sporadic entities, but family clusters have been long reported worldwide (Ishak et al., 1995; da Costa et al., 2013; Alvarez et al., 2016; Frutos et al., 2017). Members of the same family share transmission routes of infection, virus genotypes, host genetic background, and environmental factors that increase the risk for family aggregation of the virus infection and associated diseases.

The search for host immunogenetic markers, possibly associated with HTLV-1 infection and progression to disease was pursued by our research group in the Amazon region of Brazil and other groups elsewhere (Nishimura et al., 1991; Jeffery et al., 2000; Pontes et al., 2005; Alves et al., 2007; Vallinoto et al., 2012, 2015; de Sá et al., 2016; Rosado et al., 2017). Polymorphisms rs 1800450 


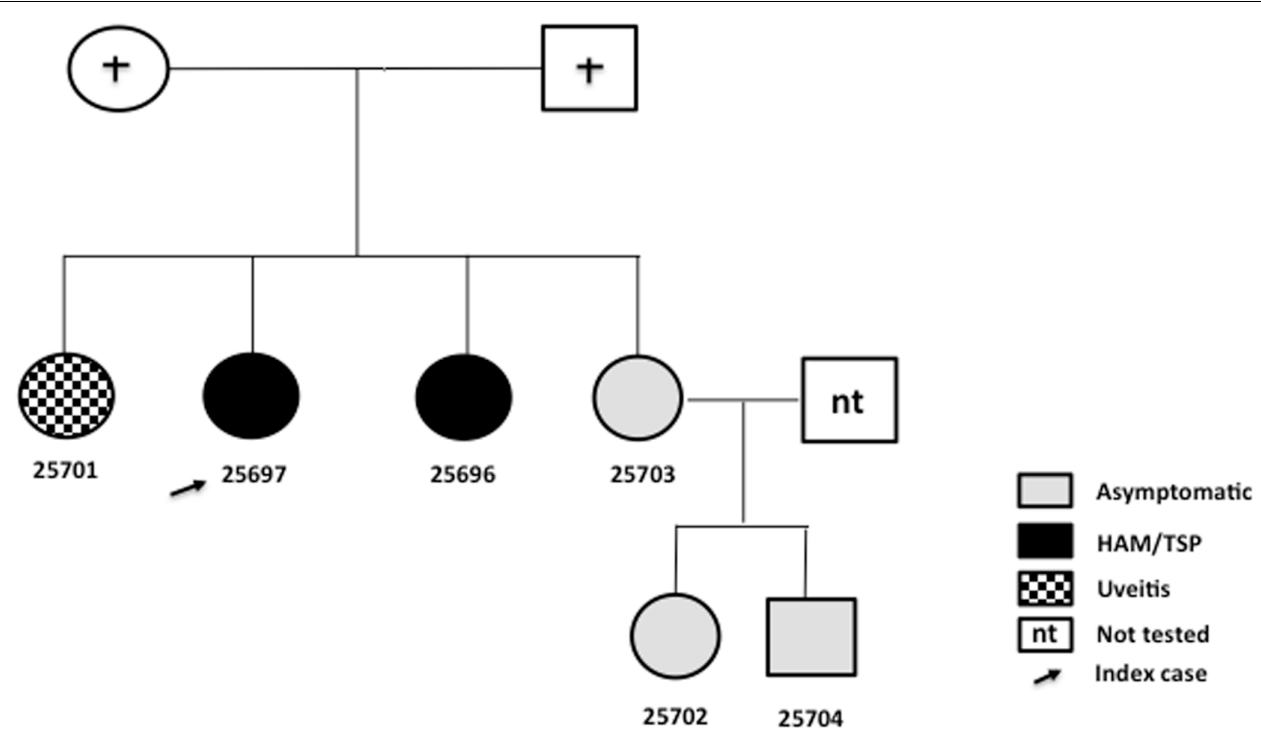

FIGURE 1 | Heredogram showing a family aggregation of HTLV-1 infection and associated diseases.

TABLE 1 | Demographic genetic and clinical information of the HTLV-1 infected family members investigated.

\begin{tabular}{|c|c|c|c|c|c|c|c|c|}
\hline Subject & Sex & Age & Kinship & Generation $\left({ }^{\circ}\right)$ & MBL2 & FAS -670 & Clinic outcome & PVL \\
\hline \#25697* & Female & 61 & - & $2^{\circ}$ & $A A$ & $A G$ & HAM/TSP & 4529.8 \\
\hline \#25696 & Female & 54 & Sister & $2^{\circ}$ & $\mathrm{AA}$ & AA & $\mathrm{HAM} / \mathrm{TSP}$ & 2437.7 \\
\hline \#25701 & Female & 65 & Sister & $2^{\circ}$ & $A B$ & $A G$ & Uveitis & 1215.0 \\
\hline \#25703 & Female & 72 & Sister & $2^{\circ}$ & $A B$ & $\mathrm{GG}$ & Asymptomatic & 1557.7 \\
\hline \#25702 & Female & 49 & Niece & $3^{\circ}$ & $\mathrm{AA}$ & $\mathrm{GG}$ & Asymptomatic & 2652.3 \\
\hline \#25704 & Male & 47 & Nephew & $3^{\circ}$ & $A B$ & $G G$ & Asymptomatic & 569.0 \\
\hline
\end{tabular}

*Index case; PVL, proviral load (copies of DNA proviral/ $/ \mathrm{mm}^{3}$ ).

(allele B, codon 54) and rs1800682 (-670A/G) located in $M B L 2$ and FAS genes, respectively, were strongly associated with HTLV-1 infection. $M B L 2^{*} B$ allele was associated with higher proviral load, a viral biomarker of disease outcome. Similarly, FAS -670A/G single nucleotide polymorphism allele ${ }^{*} G$ was more frequent among HTLV-1 asymptomatic infected persons and allele ${ }^{*} A$ was more prevalent among those with clinical neurological symptoms diagnosed as HTLV-1 associated myelopathy/Tropical spastic paraparesis (HAM/TSP). The present study aimed to investigate if a family aggregation of HTLV-1 infection could be associated with FAS and MBL2 gene polymorphisms.

\section{CASE REPORT}

The study was approved by the Research Ethics Committee of the University Hospital João de Barros Barreto from the Universidade Federal do Pará (process No. 2061/2005). Participants were fully informed about the research objectives, and those who agreed to participate signed an informed consent form.

Figure $\mathbf{1}$ and Table $\mathbf{1}$ describe a three generation family, from the Northern of Brazil (Amazon region), which included six members (five females and one male; index case \#25697). HTLV-1 infection was investigated in the plasma and cells of blood samples. An enzyme immune assay was used for the detection of antibodies to HTLV-1/2 in the plasma. Positive samples were submitted to DNA extraction from PBMC using the purification kit GFX for genomic DNA (Amersham Pharmacia Biotech, Inc., United States) and assayed using nested PCR and qPCR to confirm the infection, as previously described (da Costa et al., 2013). FAS and MBL2 gene polymorphisms were identified using a PCR method, as previously described (Pontes et al., 2005; Vallinoto et al., 2012).

Infection with HTLV-1 subtype Cosmopolitan, subgroup Transcontinental, was confirmed in the six investigated members of the family, according to the homology to sequences deposited in the NCBI - National Center for Biotechnology Information website ${ }^{1}$.

Three members of the family were asymptomatic, two presented HAM/TSP and one with uveitis. Although the precise route of transmission was not known breastfeeding was the most probable route as two sisters reported to have been breastfed by

\footnotetext{
${ }^{1}$ https://www.ncbi.nlm.nih.gov
} 
the already deceased mother. One of the four sisters (\#25703) was an asymptomatic married HTLV-1 carrier, who breastfed her two children and both were also asymptomatic HTLV-1 carriers.

$M B L 2$ gene polymorphism analysis showed the presence of AA wild genotype in three subjects. The allele $M B L 2 * \mathrm{~B}$ (rs1800450), carried by heterozygous genotype (AB), was observed in two sisters (second generation) and in one male of the third generation (Figure 1).

The investigation of FAS $-670 \mathrm{~A} / \mathrm{G}$ polymorphism showed that five members of the family $(83 \%)$ carried the allele ${ }^{*} G$; three of them were asymptomatic homozygous GG and two were symptomatic heterozygous AG, one with a clinical diagnosis of uveitis and the other with HAM/TSP. One of the females with HAM/TSP was a carrier of AA genotype. The allele ${ }^{*} G$ was more frequent among the asymptomatic persons, but the allele ${ }^{*} A$, was present among the three symptomatic sisters.

\section{DISCUSSION}

MBL is an important acute-phase serum protein involved in the innate immune response that can trigger complement activation (Wong et al., 1999), and an association between allele ${ }^{*} B$ in the exon 1 of the $M B L 2$ gene has been reported with the occurrence of immunodeficiency and chronic infectious diseases (Turner, 2003; Vallinoto et al., 2006). In our previous report, allele ${ }^{*} B$ was associated with higher proviral load, a biomarker of clinical progression for HTLV-1 associated diseases. One of the three family members carrying the allele ${ }^{*} B$ exhibited clinical symptoms of uveitis. The outcome of the other two asymptomatic carriers is still inconclusive and requires a follow up. However, two symptomatic HTLV-1 siblings (\#25696 and \#25697) carry the genotype AA, suggesting that there are other contributing factors for the progression of disease, apart from MBL2 gene SNP.

FAS $-670 \mathrm{~A} / \mathrm{G}$ polymorphism was investigated and the allele ${ }^{*} G$ was more frequent among the asymptomatic persons. Allele ${ }^{*} A$, was present in three symptomatic sisters, supporting our previous report that showed higher frequency of allele $* A$ among HAM/TSP patients as compared to HTLV-1 asymptomatic persons (Vallinoto et al., 2012). The physical location of a SNP of FAS $(-670 \mathrm{~A} / \mathrm{G})$ favor its binding to the site of the signal transducer and activator of transcription (STAT1), which would be sufficient for the up and down regulation of FAS gene (Wang et al., 2016). Our previous report describes a strong association between this SNP and HTLV-1 infection and suggests that persons with FAS -670GG genotype may have a lower affinity to STAT1 binding as compared to infected persons carrying the

\section{REFERENCES}

Alvarez, C., Gotuzzo, E., Vandamme, A. M., and Verdonck, K. (2016). Family aggregation of human T-Lymphotropic virus 1-associated diseases: a systematic review. Front. Microbiol. 7:1674. doi: 10.3389/fmicb.2016.01674

Alves, A. E., Hermes, R. B., Tamegão-Lopes, B., Machado, L. F., Azevedo, V. N., Ishak, M. O., et al. (2007). Polymorphism in the promoter region of the mannose-binding lectin gene among human T-cell lymphotropic virus infected subjects. Mem. Inst. Oswaldo Cruz 102, 991-994. doi: 10.1590/S007402762007000800015
FAS -670AA genotype. The presence of the SNP may lead to a decrease or increase of the apoptotic potential of the FAS receptor among patients carrying FAS -670GG and AA genotypes, respectively (Vallinoto et al., 2012). Farre et al. (2008) showed that the FAS promoter polymorphism is associated with the clinical manifestation and survival of HTLV-1 patients presenting adult T-cell leukemia - ATL. Among HAM/TSP patients, FAS levels correlated positively with lymphocyte activation, but the increased lymphocyte FAS expression was linked to decreased apoptosis and increased lymphoproliferation in cell culture and a strong increase in cellular FAS expression upon HAM/TSP progression (Menezes et al., 2017). Moreover, Rosado et al. (2017) found an association between the FAS -670 AA genotype and the higher proviral load among HAM/TSP patients.

It is important to point out that although familial aggregation of HTLV-1 infection and disease is not a recently described characteristic of the natural history of the virus, there are few attempts to characterize associated biomarkers, which favor the clustering of cases and define the outcome of the infection. FAS -670A/G polymorphism seems to be a reliable indicator to pursue involving larger numbers of other families with HTLV-1 aggregation. This would certainly help to assist toward prevention of the virus spread.

\section{AUTHOR CONTRIBUTIONS}

Conceived and designed the experiments: AV, MS, and RI; wrote the paper: AV, IC-V, and RI; assisted with editing the paper: MQ, AS, and IC-V; performed the experiments: BS, CC, and MQ; analyzed the data: AV, BS, RI, and MS; contributed reagents/materials/analysis tools: AV, MS, and RI.

\section{FUNDING}

The present study was supported by grants from Conselho Nacional de Desenvolvimento Científico e Tecnológico CNPq (302582/2013-4 and 459352/2014-8) and Pró-Reitoria de Pesquisa e Pós-Graduação (PROPESP/UFPA) and Pró-Reitoria de Extensão (PROEX/UFPA).

\section{ACKNOWLEDGMENTS}

The authors thank all the family members who accepted to take part of the present study.

Bangham, C. R. M., and Matsuoka, M. (2017). Human T-cell leukaemia virus type 1: parasitism and pathogenesis. Philos. Trans. R. Soc. Lond. B Biol. Sci. 372:20160272. doi: 10.1098/rstb.2016.0272

da Costa, C. A., Furtado, K. C., Ferreira, L. S., Almeida, D. S., Linhares, A. C., Ishak, R., et al. (2013). Familial transmission of human T-cell lymphotropic virus: silent dissemination of an emerging but neglected infection. PLOS Negl. Trop. Dis. 7:e2272. doi: 10.1371/journal.pntd. 0002272

de Sá, K. S., Santana, B. B., de Souza Ferreira, T. C., Sousa, R. C., Caldas, C. A., Azevedo, V. N., et al. (2016). IL28B gene polymorphisms and Th1/Th2 cytokine 
levels might be associated with HTLV-associated arthropathy. Cytokine 77, 79-87. doi: 10.1016/j.cyto.2015.11.004

Farre, L., Bittencourt, A. L., Silva-Santos, G., Almeida, A., Silva, A. C., Decanine, D., et al. (2008). Fas 670 promoter polymorphism is associated to susceptibility, clinical presentation, and survival in adult T cell leukemia. J. Leukoc. Biol. 83, 220-222. doi: 10.1189/jlb.0407198

Frutos, M. C., Gastaldello, R., Balangero, M., Remondegui, C., Blanco, S., Otsuki, K., et al. (2017). Silent dissemination of HTLV-1 in an endemic area of Argentina. Epidemiological and molecular evidence of intrafamilial transmission. PLOS ONE 12:e174920. doi: 10.1371/journal.pone.0174920

Gessain, A., and Cassar, O. (2012). Epidemiological aspects and world distribution of HTLV-1 infection. Front. Microbiol. 3:388. doi: 10.3389/fmicb.2012. 00388

Ishak, R., Harrington, W. J. Jr., Azevedo, V. N., Eiraku, N., Ishak, M. O. G., Guerreiro, J. F., et al. (1995). Identification of human T-cell lymphotropic virus type IIa infection in the Kayapo, an indigenous population of Brazil. AIDS Res. Hum. Retroviruses 11, 813-821. doi: 10.1089/aid.1995. 11.813

Jeffery, K. J., Siddiqui, A. A., Bunce, M., Lloyd, A. L., Vine, A. M., Witkover, A. D., et al. (2000). The influence of HLA class I alleles and heterozygosity on the outcome of human $\mathrm{T}$ cell lymphotropic virus type I infection. J. Immunol. 165, 7278-7284. doi: 10.4049/jimmunol.165.12.7278

Kaplan, J. E., Osame, M., Kubota, H., Igata, A., Nishitani, H., Maeda, Y., et al. (1990). The risk of development of HTLV-I-associated myelopathy/tropical spastic paraparesis among persons infected with HTLV-I. J. Acquir. Immune Defic. Syndr. 3, 1096-1101.

Menezes, S. M., Leal, F. E., Dierckx, T., Khouri, R., Decanine, D., Silva-Santos, G., et al. (2017). A fashi lymphoproliferative phenotype reveals non-apoptotic fas signaling in HTLV-1-associated neuroinflammation. Front. Immunol. 8:97. doi: 10.3389/fimmu.2017.00097

Nishimura, Y., Okubo, R., Minato, S., Itoyama, Y., Goto, I., Mori, M., et al. (1991). A possible association between HLA and HTLV-I-associated myelopathy (HAM) in Japanese. Tissue Antigens 37, 230-231. doi: 10.1111/j.1399-0039. 1991.tb01877.x

Poiesz, B. J., Ruscetti, F. W., Reitz, M. S., Kalyanaraman, V. S., and Gallo, R. C. (1981). Isolation of a new type C retrovirus (HTLV) in primary uncultured cells of a patient with Sézary T-cell leukaemia. Nature 294, 268-271. doi: 10.1038/ 294268a0

Pontes, G. S., Tamegão-Lopes, B., Machado, L. F., Azevedo, V. N., Ishak, M. O., Ishak, R., et al. (2005). Characterization of mannose-binding lectin gene polymorphism among human T-cell lymphotropic virus 1 and 2-infected asymptomatic subjects. Hum. Immunol. 66, 892-896. doi: 10.1016/j.humimm. 2005.06.006

Rosado, J., Morales, S., López, G., Clark, D., Verdonck, K., Gotuzzo, E., et al. (2017). The FAS-670 AA genotype is associated with high proviral load in peruvian HAM/TSP patients. J. Med. Virol. 89, 726-731. doi: 10.1002/jmv.24681

Turner, M. W. (2003). The role of mannose-binding lectin in health and disease. Mol. Immnunol. 40, 423-429. doi: 10.1016/S0161-5890(03)00155-X

Vallinoto, A. C., Menezes-Costa, M. R., Alves, A. E., Machado, L. F., de Azevedo, V. N., Souza, L. L., et al. (2006). Mannose-binding lectin gene polymorphism and its impact on human immunodeficiency virus 1 infection. Mol. Immunol. 43, 1358-1362. doi: 10.1016/j.molimm.2005.09.001

Vallinoto, A. C., Santana, B. B., dos Santos, E. L., Santo, R. R., Hermes, R. B., Sousa, R. C., et al. (2012). FAS -670A/G single nucleotide polymorphism may be associated with human T lymphotropic virus-1 infection and clinical evolution to TSP/HAM. Virus Res. 163, 178-182. doi: 10.1016/j.virusres.2011.09.015

Vallinoto, A. C., Santana, B. B., Sá, K. S., Ferreira, T. C., Sousa, R. C., Azevedo, V. N., et al. (2015). HTLV-1-associated myelopathy/tropical spastic paraparesis is not associated with SNP rs12979860 of the IL-28B gene. Mediators Inflamm. 2015:804167. doi: 10.1155/2015/804167

Wang, S., Wu, S., Meng, Q., Li, X., Zhang, J., Chen, R., et al. (2016). FAS rs2234767 and rs 1800682 polymorphisms jointly contributed to risk of colorectal cancer by affecting SP1/STAT1 complex recruitment to chromatin. Sci. Rep. 6:19229. doi: $10.1038 /$ srep 19229

Wong, N. K., Kojima, M., Dobó, J., Ambrus, G., and Sim, R. B. (1999). Activities of the MBL-associated serine proteases (MASPs) and their regulation by natural inhibitors. Mol. Immunol. 36, 853-861. doi: 10.1016/S0161-5890(99)00106-6

Conflict of Interest Statement: The authors declare that the research was conducted in the absence of any commercial or financial relationships that could be construed as a potential conflict of interest.

At the time of acceptance, the handling Editor declared a shared affiliation, though no other collaboration, with the authors.

Copyright (® 2018 Vallinoto, Santana, Queiroz, da Silva, Cayres-Vallinoto, da Costa, de Sousa and Ishak. This is an open-access article distributed under the terms of the Creative Commons Attribution License (CC BY). The use, distribution or reproduction in other forums is permitted, provided the original author(s) or licensor are credited and that the original publication in this journal is cited, in accordance with accepted academic practice. No use, distribution or reproduction is permitted which does not comply with these terms. 